\title{
Nitric oxide inhibits gastric cancer cell growth through the modulation of the Akt pathway
}

\author{
JIANRONG SANG, YONGCHANG CHEN and YAN TAO
}

School of Medical Science and Laboratory Medicine, Jiangsu University, Zhenjiang, Jiangsu, P.R. China

Received April 6, 2011; Accepted July 11, 2011

DOI: $10.3892 / \mathrm{mmr} .2011 .535$

\begin{abstract}
Nitric oxide (NO) is involved in a number of physiological and pathological processes. As an important biological mediator, NO has been the focus of cancer study for its function in tumorigenesis, tumor progression and death. The effects of $\mathrm{NO}$ on tumor cells are multifaceted, but many details underlying these effects are not yet well understood. In this study, we demonstrate that NO directly suppresses the growth of BGC-823 cells by inducing G0/G1 phase arrest in a dose- and time-dependent manner. We also reveal that G0/G1 arrest results from the NO-induced disruption of the cell cycle balance, which is mediated by the up-regulation of $\mathrm{p} 21^{\mathrm{wa} 1 / \mathrm{cip} 1}$ and the downregulation of cyclin D1 and E and PCNA. Exposure of BGC-823 cells to various sodium nitroprusside (SNP) concentrations for $24 \mathrm{~h}$ or to $1 \mathrm{mmol} / \mathrm{l} \mathrm{SNP}$ for various times resulted in a marked decrease in the level of phospho-Akt and increase in the level of phospho-ERK. In brief, the NO-induced cell growth suppression and G0/G1 arrest are mediated through the regulation of cell cycle-related proteins, which may depend on the inactivation of Akt signaling. This may be one mechanism through which NO inhibits gastric cancer cell growth.
\end{abstract}

\section{Introduction}

Nitric oxide (NO), a highly versatile free radical gas of physiological significance, is capable of controlling multiple cellular signaling processes in organisms ranging from bacteria to humans (1-3). It has been reported that NO is capable of inhibiting cell proliferation in certain cell types and conditions, but stimulates cell proliferation in others $(4,5)$. The dual role of $\mathrm{NO}$ depends on its concentration, action time and effector sites of generated NO (6). However, the cellular targets for NO and the related molecular mechanism remain unclear. Thus, it is essential to understand the manner in which NO controls cell proliferation.

Correspondence to: Dr Jianrong Sang, School of Medical Science and Laboratory Medicine, Jiangsu University, 301 XueFu Road, Zhenjiang, Jiangsu 212013, P.R. China

E-mail: sangjianrong@yahoo.com.cn

Key words: nitric oxide, gastric cancer cells, cell growth, Akt
Abnormal regulations of cell cycle and cell proliferation are important mechanisms of tumorigenesis. Cell cycle progression is mediated by cyclin-dependent kinases (CDK) (7). Progression in G1 phase and entry into $\mathrm{S}$ phase are related to the activity of CDK2/cyclin E complex (8). Cyclin E expression increases during G1 and peaks at G1-to-S transition. Cyclin D1 and its partners CDK4 and CDK6 have been found to be most closely linked to the late G0/G1 phase checkpoint $(9,10)$. Whether cells transit from G1 to $\mathrm{S}$ phase depends largely on the accumulation of cyclin D1 in the G1 phase. The CDK activity is also affected by cyclin-dependent kinase inhibitors (CKIs) (11). P2 $1^{\text {wafl/cip } 1}$, a CKI that interferes with cyclin $\mathrm{E}$ activity, is present in $\mathrm{CDK}$ complexes of proliferating cells during all phases of the cycle. The conversion of active into inactive complexes is achieved through alteration of the ratio of $\mathrm{p} 21^{\text {waf1/cip1 }}$ to CDK (12). The MAPK/ERK pathway has classically been associated with anti-proliferative signaling. Transient or cyclical ERK activation has been linked to cell cycle progression, whereas sustained levels of ERK activity can lead to cell growth arrest and differentiation (13). ERK phosphorylation and the up-regulation of $\mathrm{p} 21^{\text {waf1/cip1 }}$ are known to be central in NO-mediated smooth muscle cell anti-proliferation (14). It has also been demonstrated that the NO-induced deactivation of the Akt pathway plays a central role in cell growth and survival (15). NO is known to mediate the ERK pathway and inhibit Akt signaling, but the question whether it modulates gastric cancer cell growth via these pathways has yet to be investigated. In this study, BGC-823 cell lines were selected to investigate the effect of $\mathrm{NO}$, which may aid in the understanding of the effect of NO on this type of malignant tumor cell and the related mechanisms.

\section{Materials and methods}

Cell lines and reagents. The human gastric cancer cell line, BGC-823, was provided by the Institute of Cell Biology (Shanghai, China). Dulbecco's modified Eagle's medium (DMEM) was from Gibco (Grand Island, NY, USA) and new-born calf serum (NBCS) was from Minhai Bio-engineering Co. (Lanzhou, China).

Antibodies against PCNA, cyclin D1 and E, p21 $1^{\text {waf1/cip1 }}, \mathrm{p}-\mathrm{Akt}$ and Akt were from Santa Cruz Biotechnology Inc. (Heidelberg, Germany). Antibodies against proliferating cell nuclear antigen (PCNA), p-ERK and ERK were from Boster Biological Technology Ltd. (Wuhan, China). Peroxidase-conjugated 
A

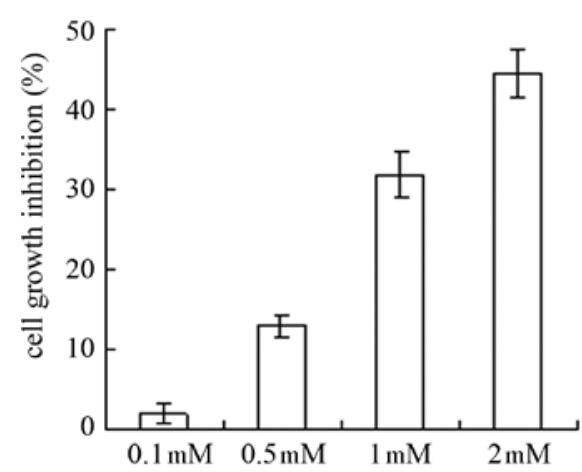

B

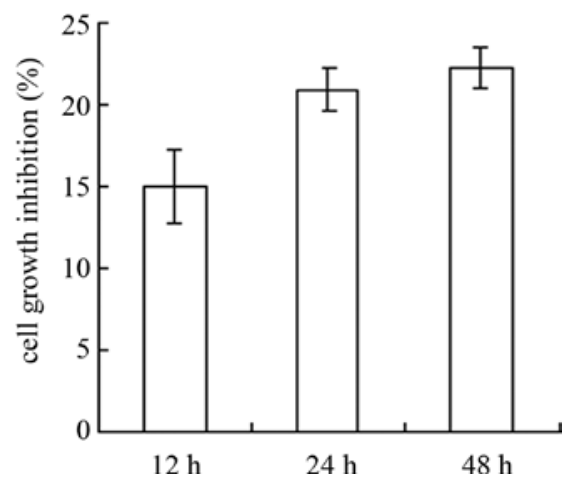

Figure 1. NO inhibits the proliferation of BGC-823 cells in a dose-dependent manner. Cells were treated with (A) various SNP concentrations for $24 \mathrm{~h}$ or (B) $1 \mathrm{mM}$ SNP for various times. Cell proliferation was examined using the MTT assay. Values are the means \pm SE of three different experiments.

secondary antibodies were from Jackson ImmunoResearch Laboratories (West Grove, PA, USA). Antibody against $\beta$-actin (glyceraldehyde phosphate dehydrogenase) was from Kangcheng (Hangzhou, China). Electrochemiluminescence (ECL) reagents were from Amersham Biosciences (Buckinghamshire, UK). All other reagents used were of analytical grade.

Cell culture. BGC-823 cells were cultured in DMEM supplemented with $10 \% \mathrm{NBCS}$ and maintained at $37^{\circ} \mathrm{C}$ in a humidified incubator with $95 \%$ air and $5 \% \mathrm{CO}_{2}$. The medium was changed every two days, and the cells were subcultured to confluence. BGC-823 cells were exposed to $0.1,0.5,1,2 \mathrm{mM}$ sodium nitroprusside (SNP) for $24 \mathrm{~h}$, or $1 \mathrm{mM} \mathrm{SNP}$ for 12,24 or $48 \mathrm{~h}$

Western blotting. The cells were harvested and homogenized with an ultrasonic homogenizer in sample buffer. The homogenates were heated in boiling water for $5 \mathrm{~min}$, separated by SDS-PAGE gels and blotted onto a polyvinyl difluoride (PVDF) membrane. The PVDF membrane was blocked with $3 \%$ bovine serum albumin in TBS-T for $1 \mathrm{~h}$ at room temperature (RT). Incubation with the primary antibody was conducted overnight at $4^{\circ} \mathrm{C}$, and incubation with the secondary antibody was for $1 \mathrm{~h}$ at RT, with three washes following each incubation. ECL reagents were used to reveal the positive bands on the membrane. The bands were detected by Typhoon 9400 (GE Healthcare, USA).

MTT assay. A total of $1 \times 10^{4}$ cells (in $100 \mu 1$ complete DMEM) were seeded in one well of a 96-well plate. Following attachment, the cells were washed and serum-starved overnight. Thereafter, the cells were incubated in $0.1,0.5,1$ or $2 \mathrm{mM}$ SNP for $24 \mathrm{~h}$ or $1 \mathrm{mM} \mathrm{SNP}$ for 12, 24 or $48 \mathrm{~h}$. Approximately $20 \mu \mathrm{l}$ of 3-(4,5-dimethylthiazol-2-yl)-2,5-dimethyl tetrazolium bromide (MTT) $(5 \mathrm{mg} / \mathrm{ml})$ were added to each well, and the plate was incubated for $4 \mathrm{~h}$. Dimethylsulfoxide (DMSO) $(150 \mu \mathrm{l})$ was added to the wells to dissolve the formazan crystals, and the optical density at $490 \mathrm{~nm}$ was measured. Data were presented as a percentage of control proliferation, and a value of $\mathrm{P}<0.05$ was considered significant.
Flow cytometric analysis of the cell cycle. BGC-823 cells were washed twice with PBS and suspended in $4 \mathrm{ml}$ of $75 \%$ ethanol. Prior to analysis, the cells were washed twice with PBS and incubated with RNase A $(10 \mu \mathrm{g} / \mathrm{ml})$ at $37^{\circ} \mathrm{C}$ for $30 \mathrm{~min}$. After being stained with Pi-staining solution in the dark for $30 \mathrm{~min}$ at RT, the cells were analyzed by flow cytometry on a FACScalibur (Becton-Dickinson).

Statistical analysis. Data were expressed as the means $\pm \mathrm{SE}$. Statistical significance was examined with the Student's t-test. A value of $\mathrm{P}<0.05$ was considered significant. All other results are representative experiments that were reproduced at least three times.

\section{Results}

NO dose-dependently inhibits the cell proliferation of gastric cancer cells. To assess whether NO regulates growth inhibition, we incubated cells with SNP. The cytotoxic effect of $\mathrm{NO}$ on the growth of gastric cancer cells was determined by MTT assay. The IC50 value in BGC-823 cells was $1.32 \mathrm{mM}$ after $24 \mathrm{~h}$ of SNP treatment (data not shown). At the same time it was shown that NO has an inhibitive effect on the proliferation of cells at various concentrations of SNP for $24 \mathrm{~h}$ in a dose-dependent manner (Fig. 1A). At a concentration of $1 \mathrm{mM}$, SNP exhibited a tendency to inhibit the BGC-823 cells at 24 and $48 \mathrm{~h}$ of treatment (Fig. 1B). However, our results showed that there was no significant difference between the two time-points $(\mathrm{P}<0.05)$. These results suggest that $\mathrm{NO}$ inhibits cell proliferation in a dose-dependent manner.

NO alters the cell cycle of gastric cancer cells. In order to investigate the reason why the proliferation of BGC-823 cells was inhibited, the cell cycle of BGC-823 cells treated with various concentrations of SNP for $24 \mathrm{~h}$ or with $1 \mathrm{mM} \mathrm{SNP}$ for various times, was analyzed. SNP decreased the number of cells in the $\mathrm{S}$ phase and increased the number of cells in the G0/G1 phase, an effect that occurred in a dose-dependent manner (Table IA). The BGC-823 cells underwent cell cycle arrest as early as $12 \mathrm{~h}$ after $1 \mathrm{mM}$ SNP treatment, while SNP 
Table I. NO induces cell cycle arrest in a dose-dependent manner in BGC-823 cells.

A, SNP concentration

\begin{tabular}{llcc}
\hline \multirow{2}{*}{$\begin{array}{l}\text { Concentration } \\
(\mathrm{mM})\end{array}$} & \multicolumn{3}{c}{ Phases of the cell cycle (\%) } \\
\cline { 2 - 4 } & $\mathrm{G} 0 / \mathrm{G} 1$ & $\mathrm{~S}$ & $\mathrm{G} 2 / \mathrm{M}$ \\
\hline 0 & $52.10 \pm 0.32$ & $46.77 \pm 0.34$ & $1.13 \pm 0.43$ \\
0.1 & $56.32 \pm 1.35$ & $42.75 \pm 0.75$ & $0.93 \pm 0.37$ \\
0.5 & $62.65 \pm 0.69^{*}$ & $36.10 \pm 0.89$ & $1.25 \pm 0.19$ \\
1 & $67.78 \pm 1.58^{*}$ & $31.23 \pm 1.01^{*}$ & $0.99 \pm 0.51$ \\
2 & $75.05 \pm 2.07^{*}$ & $23.86 \pm 2.51^{*}$ & $1.09 \pm 1.04$ \\
\hline
\end{tabular}

B, SNP exposure time

\begin{tabular}{llcc}
\hline \multirow{2}{*}{$\begin{array}{l}\text { Time } \\
\text { (h) }\end{array}$} & \multicolumn{3}{c}{ Phases of the cell cycle (\%) } \\
\cline { 2 - 4 } & G0/G1 & $\mathrm{S}$ & $\mathrm{G} 2 / \mathrm{M}$ \\
\hline 0 & $50.88 \pm 1.36$ & $47.01 \pm 1.21$ & $2.09 \pm 0.03$ \\
12 & $56.11 \pm 1.15$ & $42.43 \pm 1.03$ & $1.36 \pm 0.14$ \\
24 & $62.99 \pm 1.57^{*}$ & $35.52 \pm 1.37^{*}$ & $1.42 \pm 0.18$ \\
48 & $64.07 \pm 0.59^{*}$ & $34.80 \pm 0.89^{*}$ & $0.97 \pm 0.01$ \\
\hline
\end{tabular}

Cells were treated with (A) various SNP concentrations for $24 \mathrm{~h}$ or (B) $1 \mathrm{mM} \mathrm{SNP}$ for various times. Values are the means $\pm \mathrm{SE}$ of three different experiments. ${ }^{*} \mathrm{P}<0.05$.

hardly changed the number of cells in each phase at 48 or $24 \mathrm{~h}$ of treatment (Table IB) $(\mathrm{P}<0.05)$. These results clearly demonstrate that NO delays the conversion from the G0/G1 to the $\mathrm{S}$ phase.

NO suppresses cell-cycle protein expression. To further study the effect of $\mathrm{NO}$ on proliferation, we examined the expression of proteins involved in the cell cycle at the G1-S transition. Treatment with SNP resulted in a marked enhancement in the expression of $\mathrm{p} 21^{\mathrm{waf} 1 / \mathrm{cip} 1}$ in a time- and dose-dependent manner (Fig. 2). Analysis of the expression of cyclin E and D1 indicated that NO treatment of BGC-823 cells resulted in time- and dose-dependent reduction of their expression (Fig. 2). When we examined the expression of PCNA, a protein required for replication, that is the marker of proliferating cells, we observed a comparable result. The PCNA levels were reduced at $12 \mathrm{~h}$ following SNP treatment (Fig. 2B). The reduction of the expression of cyclin E, cyclin D1 and PCNA indicates that NO suppresses cell proliferation by blocking G1-S phase transition in the cell cycle. Consistent with the initial inhibition of cell growth, SNP treatment resulted in G0/G1 arrest, which manifested as an increased G0/G1 content and decreased S phase content in a dose- and time-dependent manner. Thus, our data demonstrate that NO induces cell cycle arrest at the G0/G1 phase.

NO inhibits Akt and activates ERK. The mechanism under $\mathrm{NO}$-induced cell growth inhibition and cell cycle arrest in BGC-823 cells was investigated. The MAP kinase cascade is important for cell proliferation, differentiation and apoptosis (16). The Ser/Thr protein kinase, Akt, is recognized as one of the main downstream effectors of PI3K that promote cell proliferation and survival (17-20). In order to verify the effect of SNP on the activities of ERK and Akt, we performed experiments measuring the expressions and the phosphorylation levels of ERK and Akt in gastric cancer cells. As shown in Fig. 3, exposure of BGC-823 cells to $1 \mathrm{mM} \mathrm{SNP}$ for 12-48 h resulted in a marked decrease in Akt phosphorylation. Simultaneously, a decreased phospho-Akt level was observed with the increase of the concentration of SNP. However, NO-induced time- and dose-dependent increases in phosphoERK were observed. These results indicate that the effect of $\mathrm{NO}$ on BGC-823 cell proliferation does not involve the ERK pathway and that NO induces cell cycle arrest through the inhibition of phospho-Akt levels.

\section{Discussion}

It has been demonstrated that $\mathrm{NO}$ is involved in diverse processes in cellular signaling and in the potentiation of numerous tumors. Studies have already revealed that NO inhibits cell growth and induces apoptosis in various cells, including tumor cells. Similar results were obtained in our study by evaluating the effect of SNP, a NO donor, on the
A

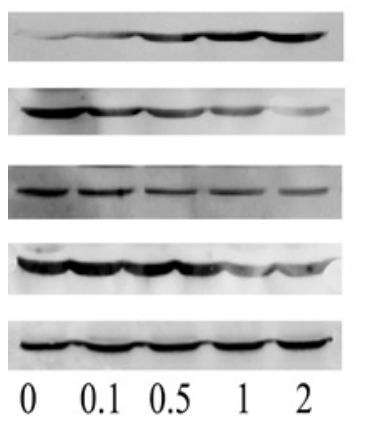

p21

cyclin D1

cyclin $\mathrm{E}$

PCNA

$\beta$-actin
B

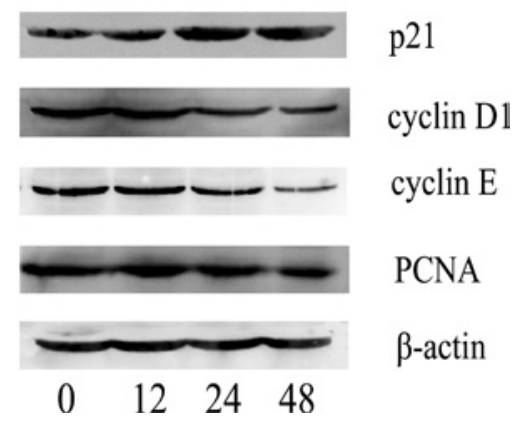

Figure 2. Effects of NO on G1/G1 cell cycle regulatory proteins in BGC-823 cells. Cells were treated with (A) various SNP concentrations for 24 h or (B) $1 \mathrm{mM}$ SNP for various times and the expression of $\mathrm{p} 21^{\text {waf } 1 / \mathrm{cip} 1}$, cyclin D1, and cyclin E was determined by Western blot analysis. The experiments were repeated at least three times with similar results. 
A

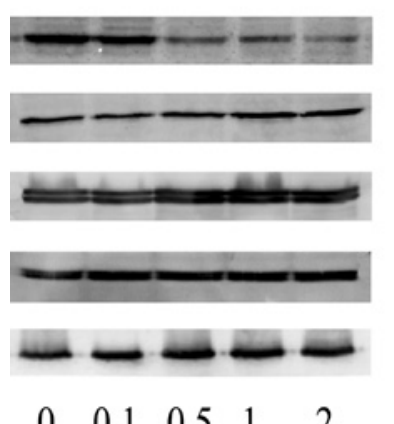

p-Akt

Akt

p-ERK

ERK

$\beta$-actin

$\begin{array}{lllll}0 & 0.1 & 0.5 & 1 & 2\end{array}$

B

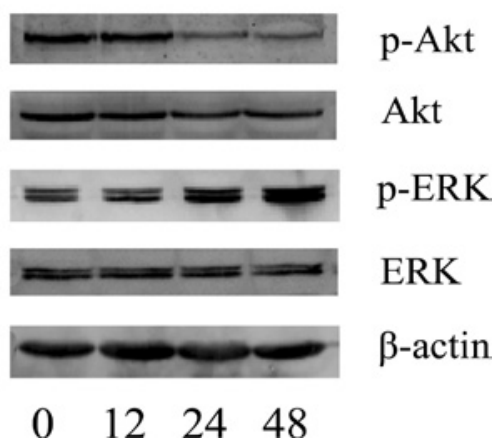

Figure 3. Effects of $\mathrm{NO}$ on the activation of ERK and Akt in BGC-823 cancer cells. Cells were treated with (A) various SNP concentrations for 24 h or (B) $1 \mathrm{mM}$ SNP for various times and the expression of the phospho-protein was determined by Western blot analysis. The experiments were repeated at least three times with similar results.

proliferation in BGC-823 cells. BGC-823 cells were treated with various concentrations of SNP for various times. As shown in Fig. 1, the proliferation of BGC-823 cells was significantly inhibited by $\mathrm{NO}$, with more potent blocking when increasing concentrations of SNP were used. Furthermore, our results have shown that the significant growth-inhibiting effect of NO on BGC-823 cells was observed when the cells were exposed to SNP for as long as $48 \mathrm{~h}$, indicating that NO-mediated inhibition of cell proliferation lasts for a prolonged period of time.

The cell cycle analysis revealed that, in SNP-treated BGC-823 cells, the significant decrease of $\mathrm{S}$ phase cells was accompanied by an increase of G0/G1 phase cells and no change of G2/M phase cells. Thus, the decrease of cell numbers in the $\mathrm{S}$ phase was clearly due to the increase of cells in the G0/G1 phase, and the blockade effect of NO occurred at the G1-S transition. The data indicated that there was no significant difference between the cell numbers in each phase from 24 to $48 \mathrm{~h}$ at the same concentration.

The changes of multiple regulators associated with the cell cycle were investigated in order to further elucidate the mechanism of action of NO. PCNA has often been considered as a marker of cells undergoing the proliferation process (21). Cyclin E and D1 are required for cell cycle G1/S transition (22). The expression of cyclin D1 is modulated by $\mathrm{p} 21^{\text {waf } 1 / \text { cip1 } 1}$. As shown in Fig. 3, the levels of cyclin D1 were suppressed as those of $\mathrm{p} 21^{\text {wafl/cipl }}$ increased, which was in agreement with the known regulatory relationship between the two proteins. Our data also revealed that NO down-regulated the levels of cyclin $\mathrm{E}$ in a time- and dose-dependent manner, thus providing a possible explanation for the observed S-phase arrest induced by NO. Simultaneously, 12-48 h treatment of SNP significantly down-regulated the expression of PCNA, which controls the progression of cells through the $S$ phase of the cell cycle. Taken together, NO induced cell growth arrest via down-regulation of the expression of cyclin D1 and E and PCNA, and up-regulation of $\mathrm{p} 21^{\text {wafl/cipl }}$ expression in gastric cancer cells.

The blockade of the MAP kinase cascade is known to inhibit cell proliferation in certain cell populations (23-25). However, the effect of $\mathrm{NO}$ on gastric cancer cell proliferation does not seem to be involved in the inhibition of this pathway, as NO increases ERK activation in BGC-823 cells. One possibility is that the NO-mediated activation of the MAP kinase cascade is involved in other physiological events, such as survival and differentiation (26-27). Cyclin E and D1 and p21 $1^{\text {wafl/cipl }}$, the key signaling downstream molecules, were activated in response to MAPK activation, ultimately leading to cell cycle deceleration and the activation of cell anti-proliferation. Our results indicate that Akt may be involved in NO-induced anti-proliferation, as the levels of phospho-Akt were significantly reduced by NO following the exposure of BGC-823 cells to various SNP concentrations for various times.

In conclusion, we observed that $\mathrm{NO}$ inhibited the growth of cancer cells by blocking the cell cycle at the $\mathrm{G} 0 / \mathrm{G} 1$ phase. We also provide mechanistic evidence that the NO-induced G0/G1 arrest is mediated through regulation of the cell cycle-related protein, which is likely to be associated with inactivation of the Akt pathway. However, the association between the down-regulation of cell cycle regulatory molecules and the phosphorylation changes of ERK and Akt in NO-treated cells is not fully understood and warrants further investigation.

\section{Acknowledgements}

This study was supported by grants from the National Natural Science Foundation of China (nos. 81001100 and 31140005, and from the Specialized Research Fund for Senior Personnel Program of Jiangsu University (no. 08JDG033).

\section{References}

1. Gow AJ and Ischiropoulos H: Nitric oxide chemistry and cellular signaling. J Cell Physiol 187: 277-282, 2001.

2. Davis KL, Martin E, Turko IV and Murad F: Novel effects of nitric oxide. Annu Rev Pharmacol Toxicol 41: 203-236, 2001.

3. Contestabile A, Monti B and Ciani E: Brain nitric oxide and its dual role in neurodegeneration/neuroprotection: understanding molecular mechanisms to devise drug approaches. Curr Med Chem 10: 2147-2174, 2003.

4. Villalobo A: Nitric oxide and cell proliferation. FEBS J 273: 2329-2344, 2006.

5. Villalobo A: Enhanced cell proliferation induced by nitric oxide. Dyn Cell Biol 1: 60-64, 2007.

6. Wang $\mathrm{Y}$, Ding $\mathrm{H}$ and Xiao GF: esearch advances on tumor therapy via nitric oxide. Chin J Cancer 23: 476-479, 2004.

7. Sherr CJ: Cancer cell cycles. Science 274: 1672-1677, 1996. 
8. Sherr CJ: G1 phase progression: cycling on cue. Cell 79: 551-555, 1994.

9. Jin ZH, Kurosu T, Yamaguchi M, Arai A and Miura O: Hematopoietic cytokines enhance Chk1-dependent G2/M checkpoint activation by etoposide through the Akt/GSK3 pathway to inhibit apoptosis. Oncogene 24: 1973-1981, 2005.

10. Siebert R, Willers CP and Opalka B: Role of the cyclin-dependent kinase 4 and 6 inhibitor gene family p15, p16, p18 and p19 in leukemia and lymphoma. Leuk Lymphoma 23: 505-520, 1996.

11. Sherr CJ and Roberts JM: Inhibitors of mammalian G1 cyclindependent kinases. Genes Dev 9: 1149-1163, 1995.

12. Zhang H, Hannon GJ and Beach D: p21-containing cyclin kinases exist in both active and inactive states. Genes Dev 8: 1750-1758, 1994

13. Clark JA, Black AR, Leontieva OV, Frey MR, Pysz MA, Kunneva L, Woloszynska-Read A, Roy D and Black JD: Involvement of the ERK signaling cascade in protein kinase C-mediated cell cycle arrest in intestinal epithelial cells. J Biol Chem 279: 9233-9247, 2004

14. Zuckerbraun BS, Stoyanovsky DA, Sengupta R, Shapiro RA, Ozanich BA, Rao J, Barbato JE and Tzeng E: Nitric oxideinduced inhibition of smooth muscle cell proliferation involves S-nitrosation and inactivation of RhoA. Am J Physiol Cell Physiol 292: 824-831, 2007.

15. Wang XJ, SunHY and Li CL: Nitric oxide induces promyelocytic cell growth arrest and apoptosis through deactivation of Akt pathway. Leuk Res 31: 653-660, 2007.

16. Oh-hashi K, Maruyama W, Yi H, Takahashi T, Naoi M and Isobe $\mathrm{K}$ : Mitogen-activated protein kinase pathway mediates peroxynitrite-induced apoptosis in human dopaminergic neuroblastoma SH-SY5Y cells. Biochem Biophys Res Commun 263 504-509, 1999

17. Iwata N, Tamekane A,Yakushijin K, Nishikawa S, Hamaguchi M, Fukui C, Yamamoto $\mathrm{K}$ and Matsui T: Casein kinase Iepsilon downregulates phospho-Akt via PTEN, following genotoxic stress-induced apoptosis in hematopoietic cells. Life Sci 78 : $1624-1629,2006$
18. Hammerman PS, Fox CJ, Birnbaum MJ and Thompson CB: Pim and Akt oncogenes are independent regulators of hematopoietic cell growth and survival. Blood 105: 4477-4483, 2005.

19. Jin ZH, Kurosu T, Yamaguchi M, Arai A and Miura O: Hematopoietic cytokines enhance Chk1-dependent G2/M checkpoint activation by etoposide through the Akt/GSK3 pathway to inhibit apoptosis. Oncogene 24: 1973-1981, 2005.

20. Bertrand FE, Steelman LS, Chappell WH, Abrams SL, Shelton JG, White ER, Ludwig DL and McCubrey JA: Synergy between an IGF-1R antibody and Raf/MEK/ERK and PI3K/ $\mathrm{Akt} / \mathrm{mTOR}$ pathway inhibitors in suppressing IGF-1R-mediated growth in hematopoietic cells. Leukemia 20: 1254-1260, 2006.

21. Eldrige SR, Butterworth BE and Goldsworthy TL: Proliferating cell nuclear antigen: a marker for hepatocellular proliferation in rodents. Environ Health Perspect 101 (Suppl 5): 211-218, 1993.

22. Santamaria D and Ortega S: Cyclins and CDKS in development and cancer: lessons from genetically modified mice. Front Biosci 11: 1164-1188, 2006

23. Horne MM and Guadagno TM: A requirement for MAP kinase in the assembly and maintenance of the mitotic spindle. J Cell Biol 161: 1021-1028, 2003.

24. Friday BB and Adjei AA: Advances in targeting the Ras/Raf/ MEK/Erk mitogen-activated protein kinase cascade with MEK inhibitors for cancer therapy. Clin Cancer Res 14: 342-346, 2008.

25. Roberts PJ and Der CJ: Targeting the Raf-MEK-ERK mitogenactivated protein kinase cascade for the treatment of cancer. Oncogene 26: 3291-3310, 2007.

26. Hardingham GE, Arnold FJ and Bading H: A calcium microdomain near NMDA receptors: on switch for ERK-dependent synapse-to-nucleus communication. Nat Neurosci 4: 565-566, 2001.

27. Lee J, Hong F, Dwon S, Kim SS, Kim OD, Kang HS, Lee SJ, Ha J and Kim SS: Activation of p38, MAPK induces cell cycle arrest via inhibition of Raf/ERK pathway during muscle differentiation. Biochem Biophys Res Commun 298: 765-771, 2002. 